\title{
Short message service (SMS) reminders and real- time adherence monitoring improve antiretroviral therapy adherence in rural Uganda
}

\section{Citation}

Haberer, Jessica E., Angella Musiimenta, Esther C. Atukunda, Nicholas Musinguzi, Monique A. Wyatt, Norma C. Ware, and David R. Bangsberg. 2016. "Short message service (SMS) reminders and real-time adherence monitoring improve antiretroviral therapy adherence in rural Uganda." AIDS (London, England) 30 (8): 1295-1299. doi:10.1097/QAD.0000000000001021. http://dx.doi.org/10.1097/QAD.0000000000001021.

\section{Published Version}

doi:10.1097/QAD.0000000000001021

\section{Permanent link}

http://nrs.harvard.edu/urn-3:HUL.InstRepos:27320475

\section{Terms of Use}

This article was downloaded from Harvard University's DASH repository, and is made available under the terms and conditions applicable to Other Posted Material, as set forth at http:// nrs.harvard.edu/urn-3:HUL.InstRepos:dash.current.terms-of-use\#LAA

\section{Share Your Story}

The Harvard community has made this article openly available.

Please share how this access benefits you. Submit a story.

Accessibility 


\title{
Short message service (SMS) reminders and real-time adherence monitoring improve antiretroviral therapy adherence in rural Uganda
}

\author{
Jessica E. Haberer ${ }^{a, b}$, Angella Musiimenta ${ }^{c}$, Esther C. Atukunda ${ }^{c}$, \\ Nicholas Musinguzic ${ }^{\mathrm{c}}$, Monique A. Wyatt ${ }^{\mathrm{b}}$, Norma C. Ware ${ }^{\mathrm{b}}$ \\ and David R. Bangsberg ${ }^{a, b, c, d}$
}

\section{See related paper on pages 1287 and 1301}

Objective: To explore the effects of four types of short message service (SMS) plus realtime adherence monitoring on antiretroviral therapy (ART) adherence: daily reminders, weekly reminders, reminders triggered after a late or missed dose (delivered to patients), and notifications triggered by sustained adherence lapses (delivered to patient-nominated social supporters).

Design: Pilot randomized controlled trial.

Methods: Sixty-three individuals initiating ART received a real-time adherence monitor and were randomized (1:1:1): (1) Scheduled SMS reminders (daily for 1 month, weekly for 2 months), then SMS reminders triggered by a late or missed dose (no monitoring signal within $2 \mathrm{~h}$ of expected dosing); SMS notifications to social supporters for sustained adherence lapses (no monitoring signal for $>48 \mathrm{~h}$ ) added after 3 months. (2) Triggered SMS reminders starting at enrolment; SMS notifications to social supporters added after 3 months. (3) Control: No SMS. HIV RNA was determined at 9 months. Percentage adherence and adherence lapses were compared by linear generalized estimating equations and Poisson regression, respectively.

Results: Median age was 31 years, $65 \%$ were women, and median enrolment CD4 ${ }^{+}$ cell count was 322 cells/ $\mu$ l 97\% took once daily tenofovir/emtricitabine/efavirenz. Compared to control, adherence was $11.1 \%$ higher $(P=0.04)$ and more than $48-\mathrm{h}$ lapses were less frequent (IRR 0.6, $P=0.02$ ) in the scheduled SMS arm. Adherence and more than 48-h lapses were similar in the triggered SMS arm and control. No differences in HIV RNA were seen.

Conclusion: Scheduled SMS reminders improved ART in the context of real-time monitoring. Larger studies are needed to determine the impact of triggered reminders and role of social supporters in improving adherence.

Copyright (c) 2016 Wolters Kluwer Health, Inc. All rights reserved.

AIDS 2016, 30:1295-1299

Keywords: antiretroviral therapy, real-time adherence monitoring, short message service (SMS)

\footnotetext{
a Massachusetts General Hospital, Boston, ${ }^{\mathrm{b}}$ Harvard Medical School, Boston, Massachusetts, USA, ${ }^{\mathrm{C}}$ Mbarara University of Science and Technology, Mbarara, Uganda, and ${ }^{\mathrm{d} H a r v a r d ~ T H}$ Chan School of Public Health, Boston, Massachusetts, USA

Correspondence to Jessica E. Haberer, Massachusetts General Hospital Center for Global Health, 125 Nashua St, Suite 722 , Boston, MA 02114, USA.

Tel: +1 617724 0351; e-mail: jhaberer@mgh.harvard.edu

Received: 4 November 2015; revised: 21 December 2015; accepted: 4 January 2016.
} 


\section{Introduction}

Cellular phone technology is a promising tool for antiretroviral therapy (ART) adherence support [1], although findings have been mixed. Adherence improved with weekly short message service (SMS) reminders in Kenya [2,3] and twice weekly SMS reminders in Nigeria [4], whereas no benefit was observed with weekly SMS reminders in Cameroon [5] and India [6], or with SMS reminders 5 days a week in Brazil [7].

Real-time adherence monitoring can be accomplished through pill bottles that record a date-and-time stamp for each opening, which is then transmitted over cellular networks. It is the only monitoring approach that can trigger an intervention precisely when needed. Two recent studies assessed the combination of real-time adherence monitoring with SMS reminders triggered by late or missed doses. One in China showed an improvement in overall adherence [8], whereas one in South Africa did not [9], although the latter found fewer sustained adherence lapses. SMS could also be used to engage social support systems, which have been shown to be important for ART adherence [10-12]; however, this type of intervention has not been previously studied.

Given the variable results in the literature, we conducted a pilot randomized controlled trial of multiple types of interventions based on SMS and real-time adherence monitoring to improve adherence among individuals initiating ART in Uganda.

\section{Methods}

\section{Setting}

Participants were recruited from the Mbarara Regional Referral Hospital (MRRH) in southwestern Uganda, which cares for $\sim 10000$ HIV-positive individuals. The region is largely rural and approximately one-quarter of homes have electricity.

\section{Participants}

This study involved two types of participants: individuals taking ART ('study participants') and their 'social supporters'. Inclusion criteria for study participants were: being $18+$ years, initiating ART, owning a personal cell phone with reliable reception, willing and able to identify one to two social supporters, and living less than $20 \mathrm{~km}$ from MRRH (to facilitate participant follow-up). Inclusion criteria for social supporters were: being $18+$ years, owning a personal cell phone with a reliable reception, knowing the study participant's HIV status, living less than $20 \mathrm{~km}$ from MRRH, and reporting prior provision of social support to the study participant (i.e. instrumental support to attend clinic or motivational support to take medicine). Exclusion criteria for both participant types were: inability to use SMS, unwillingness to have cellular reception confirmed at home, and inability to provide informed consent.

\section{Procedures}

All study participants received a real-time adherence monitor (Wisepill Technologies, Cape Town, South Africa) and were followed for 9 months. Monitor openings during periods of inadequate cellular reception were stored for later transmission. Participants were given solar chargers and sent an SMS to charge the monitor as needed.

A simple random number generator was used to determine study arm assignments. The study coordinator informed research assistants of the arm assignment at enrolment. Participants were randomized $1: 1: 1$ as follows:

(1) Scheduled SMS + real-time adherence monitoring ('scheduled SMS arm') - Study participants received an SMS reminder daily for 1 month, then weekly for 2 months. For the next 6 months, study participants received an SMS only if no signal was received from the monitor within $2 \mathrm{~h}$ of the expected dosing time, and an SMS notification was sent to one to two social supporters if no signal was received for more than $48 \mathrm{~h}$.

(2) Triggered SMS + real-time adherence monitoring ('triggered SMS arm') - For the whole 9 months, study participants received an SMS only if no signal was received from the monitor within $2 \mathrm{~h}$ of the expected dosing time. For the latter 6 of the 9 months, an SMS notification was sent to one to two social supporters if no signal was received for $>48 \mathrm{~h}$.

(3) Real-time adherence monitoring only (called the 'control') - Study participants in this arm received no SMS reminders.

Social supporters were encouraged to support the study participant's adherence, but were not given specific guidance. All SMS content could be personalized; the default message was 'This is your reminder'. Scheduled SMS were sent at participant-specified times.

Participants completed a questionnaire regarding sociodemographics, health, depression [13], food insecurity [14], alcohol use [15], social support [16], and HIV stigma [17]. HIV RNA was determined at months 3 and 9 (Cobas Taqman Test, Roche, Switzerland). Social supporters were enrolled during month 3 to ensure ongoing relationships when the SMS notifications began. Qualitative interviews conducted during the study are presented in a companion article [18].

\section{Analysis}

Assuming a standard deviation of $10 \%$, we determined a sample size of 63 would allow $84 \%$ power to detect an increase in mean adherence from 80 to $90 \%$ for each arm compared with control. Study participant characteristics were compared across study arms with Fisher's exact test and the Wilcoxon rank-sum test. Our primary outcome 
of interest was adherence (calculated as the number of monitor opening signals received divided by the number of monitor opening signals expected, and capped at 100\%). Monitor openings by staff were removed. A secondary dataset was created in which suspected technical difficulties or monitor nonuse per participant report was censored. Although subject to recall and social desirability biases, the secondary dataset may decrease misclassification bias. In an intention-to-treat analysis, percentage doses taken each month were compared by linear generalized estimating equations (GEEs); more than 48-h and more than 96-h lapses in dosing were compared by Poisson GEE regression. HIV RNA suppression ( $<100$ copies/ml) was compared among study arms by Fisher's exact test. To compare adherence with HIV RNA, we ran the rank-sum test for median adherence among participants with suppressed versus unsuppressed HIV RNA. Loss to follow-up was defined as no contact or adherence data for 3 months. Missing adherence data was considered as nonadherence; HIV RNA was considered unsuppressed if no blood sample was obtained. All analyses were conducted in Stata (StataCorp., College Station, Texas, USA).

\section{Ethics}

Human subject approval was obtained from Mbarara University of Science and Technology, Uganda National Council of Science and Technology, and Partners Healthcare.

\section{Results}

\section{Participant characteristics}

Between September 2013 and October 2014, 195 individuals were screened to identify 63 eligible study participants. Reasons for exclusion were (multiple criteria applied to some individuals):

(1) Lived more than $20 \mathrm{~km}$ from MRRH: 75 (57\%)

(2) No personal cell phone: 49 (37\%)

(3) Not willing or able to name one to two social supporters: $20(15 \%)$

(4) Unwilling to have cell reception tested at home: $6(5 \%)$

(5) Inability to provide informed consent: 3 (2\%)

(6) Inadequate cellular reception: $2(2 \%)$

(7) Less than 18 years old: 1 (1\%)

Twenty-one participants were assigned to the scheduled SMS arm, 20 to the triggered SMS arm, and 21 to the control. One participant was found to be HIV-negative after randomization and disenrolled; data for this participant were excluded from analysis. Forty-eight individuals were identified as social supporters, of whom 45 enrolled; the three ineligible individuals lived more than $20 \mathrm{~km}$ from MRRH. Follow-up concluded as planned in June 2015.

Fifty-eight (94\%) study participants completed the study with a median follow-up of 8.9 months [interquartile range (IQR) 8.7-8.9]. Four study participants were lost to follow-up (two in the triggered SMS arm, two in the control). Forty-one social supporters completed the study. One social supporter died, one was lost-to-followup, and two were disenrolled per the study participant's request.

Participant characteristics are presented in Table 1. All were similar among study arms with the exception of female gender ( $71 \%$ in the schedule SMS arm, 35\% in the triggered SMS arm, $86 \%$ in the control; $P=0.03$ ).

Table 1. Study participant and social supporter characteristics at enrolment.

\begin{tabular}{|c|c|c|}
\hline & Study participants $(N=62)$ & Social supporters $(N=45)$ \\
\hline & \multicolumn{2}{|c|}{$N(\%)$ or median (IQR) } \\
\hline Female & $40(65 \%)^{\mathrm{a}}$ & $31(69 \%)$ \\
\hline Median age (years) & $30(25-35)$ & $35(31-46)$ \\
\hline \multicolumn{3}{|l|}{ Education } \\
\hline None & $5(8 \%)$ & $3(7 \%)$ \\
\hline Primary & $36(58 \%)$ & $22(49 \%)$ \\
\hline Greater than primary & $21(34 \%)$ & $20(44 \%)$ \\
\hline Able to read English or Runyankole & $60(97 \%)$ & $43(96 \%)$ \\
\hline Median $\mathrm{CD} 4{ }^{+}$cell count $($cells/ $\mu \mathrm{l})$ & $309(231-397)$ & $\mathrm{n} / \mathrm{a}$ \\
\hline \multicolumn{3}{|l|}{ ART regimen } \\
\hline TDF-3TC-EFV & $60(97 \%)$ & $\mathrm{n} / \mathrm{a}$ \\
\hline ZDV-3TC-NVP & $2(3 \%)$ & $\mathrm{n} / \mathrm{a}$ \\
\hline Severe food insecurity & $23(37 \%)$ & $14(31 \%)$ \\
\hline Depression & $30(48 \%)$ & $1(2 \%)$ \\
\hline Hazardous alcohol use & $14(23 \%)$ & $6(13 \%)$ \\
\hline Social support score ${ }^{\mathrm{b}}$ & $3.1(2.8-3.4)$ & $3.1(2.6-3.7)$ \\
\hline Stigma score $\mathrm{c}^{\mathrm{c}}$ & $3(2-5)$ & $0(0-1.25)$ \\
\hline
\end{tabular}

Social supporters were only enrolled for study participants in the intervention arms. ART, antiretroviral therapy; EFV, efavirenz; NVP, nevirapine; TDF, tenofovir; ZDV, zidovudine; 3TC, lamivudine.

${ }^{a}$ Female gender was noted to be different among the randomized study arms (71\% in the schedule SMS arm, 35\% in the triggered SMS arm, $86 \%$ in the control; $P=0.03$ ). All other characteristics were similar among study arms.

${ }^{\mathrm{b}}$ This score ranges from 1 to 4 , with 4 indicating high levels of social support. 
Table 2. Comparison of adherence by study arm over the 9-month study period.

\begin{tabular}{|c|c|c|c|}
\hline & \multicolumn{3}{|c|}{ Study arm } \\
\hline & $\begin{array}{l}\text { Scheduled SMS + } \\
\text { real-time monitoring }\end{array}$ & $\begin{array}{l}\text { Triggered SMS + } \\
\text { real-time monitoring }\end{array}$ & $\begin{array}{l}\text { Control (real-time } \\
\text { monitoring only) }\end{array}$ \\
\hline \multicolumn{4}{|l|}{ Percentage adherence } \\
\hline Median (IQR) & $92 \%(88-99)$ & $84 \%(66-93)$ & $90 \%(72-93)$ \\
\hline Mean (SD) & $91 \%(9)$ & $79 \%(18)$ & $79 \%(22)$ \\
\hline Intervention effect ( $P$ value) & $11.1(0.02)$ & $-0.7(0.90)$ & ref \\
\hline \multicolumn{4}{|l|}{ Lapses in adherence } \\
\hline \multicolumn{4}{|l|}{ More than $48 \mathrm{~h}$} \\
\hline Median (IQR) & $5(1-11)$ & $8(4-16)$ & $6(3-19)$ \\
\hline Mean (SD) & $7(8)$ & $11(10)$ & $11(11)$ \\
\hline Intervention effect ( $P$ value) & $0.6(0.02)$ & $1.0(0.80)$ & ref \\
\hline \multicolumn{4}{|l|}{ More than $96 \mathrm{~h}$} \\
\hline Median (IQR) & $1(0-1)$ & $2(0-6)$ & $2(1-3)$ \\
\hline Mean (SD) & $1(2)$ & $3(3)$ & $4(5)$ \\
\hline Intervention effect ( $P$ value) & $0.3(<0.001)$ & $0.7(0.23)$ & ref \\
\hline
\end{tabular}

Intervention effects for percentage adherence reflect the difference in mean adherence, whereas intervention effects for lapses in the real-time monitoring signal indicate the incremental risk ratio. These results were found in the primary dataset in which only staff openings were censored. Results for the secondary dataset, in which suspected technical difficulties and device nonuse were also censored, were similar. IQR, interquartile range; SD, standard deviation. Significant values $(P<0.05)$ are bolded.

\section{SMS}

During the study, 3436 (63\%) SMS were sent as planned and 1935 (36\%) were sent unnecessarily (i.e. the monitor was opened, but no signal was received until after an SMS had been sent). Forty-four (1\%) SMS were not sent because of technical challenges (e.g. network outages).

\section{Adherence}

Percentage adherence was $11.1 \%$ higher $(P=0.02)$ and more than 48-h and more than 96-h lapses were less frequent [incremental risk ratio (IRR) $0.6, P=0.02$ and IRR $0.3, P<0.001$, respectively] in the scheduled SMS arm compared with the control (Table 2). Adherence was similar in the triggered SMS arm and control, although the frequency of more than 96-h adherence lapses showed a downward trend in the triggered SMS arm.

In the secondary dataset, $2 \%$ of participant-days were censored for suspected monitor nonuse and 3\% for technical difficulties; no statistically significant differences in the analysis were seen. No statistically significant differences were seen when controlling for sex differences among study arms.

\section{HIV RNA suppression}

HIV RNA was suppressed in 53 of 62 (85\%) participants at months 3 and 9, although only 47 participants were suppressed at both time points. No statistically significant differences in HIV RNA suppression were seen among study arms $(P=0.14)$; however, adherence correlated with HIV RNA. At month 9, median adherence was 91 (IQR 82-96) for participants with suppressed HIV RNA versus 57 (IQR 47-78) for those with unsuppressed HIV RNA $(P<0.001)$.

\section{Discussion}

In the context of real-time monitoring, daily and then weekly scheduled SMS reminders starting at ART initiation improved adherence compared with real-time monitoring alone, whereas SMS reminders linked to late or missed doses did not. Our findings confirm the positive impact of fixed interval reminders in prior studies [2-4]. In one of these studies, daily reminders were not effective, but weekly reminders were [3]; however, daily messages were sent for 48 consecutive weeks, potentially causing habituation. The decreasing frequency of SMS reminders in this study may have avoided that phenomenon.

Although prior studies saw significant benefit in overall adherence [8] and adherence lapses [9] with SMS linked to real-time detection of late or missed doses, we did not. Potential explanations include the overall high adherence in this study and the small sample size. Additionally, qualitative data from this study (presented separately) [18] indicate that scheduled reminders were experienced as supportive, whereas triggered reminders could be received too late to be effective (i.e., after participants were asleep).

The lack of definitive benefit from SMS notifications to social supporters was surprising. Social support has been shown previously to be important for ART adherence (e.g., via access to resources and reduced stigma) [10-12]. Detailed assessment of the support provided and relationship dynamics between study participants and social supporters will be important to understand this finding.

Similar viral suppression among study arms is consistent with the two other studies of real-time adherence interventions [8,9]. Importantly, this study was not 
powered for differences in viral suppression. It is possible that differences in virologic outcomes could be seen in a larger study with longer follow-up.

This study has important limitations. Real-time monitoring in the control group likely has its own intervention effect and may have limited the ability to detect intervention effects from SMS in the other study arms - a phenomenon explored in the separately presented qualitative findings [18]. Additionally, 37\% of screened participants were excluded because they lacked access to a personal cell phone. Participants may have had relatively high socioeconomic status, thus limiting generalizability.

In summary, we found that scheduled SMS significantly increased adherence in individuals initiating ART in Uganda. The technology employed for real-time adherence monitoring and accompanying SMS was successfully implemented despite limited resources. Future work should assess costs of this technology to inform scalability. Studies are also needed to determine the benefits associated with SMS alone versus SMS tied to real-time adherence monitoring.

\section{Acknowledgements}

The authors would like to acknowledge the contributions of Justus Ashaba, Judith Namanya, Moonlight Sheila, Moran Owembabazi, Emily Pisarski, and Melanie Tam as well as those of Wisepill Technologies, Dimagi, and Yo! Voice Solutions. The authors have no financial relationships with any of the technological partners in this study.

Funding: The study was funded by a grant from the US National Institutes of Health (R34MH100940). The study was registered with ClinicalTrials.gov (NCT01957865).

Contributions of the authors: J.E.H., A.M., and D.R.B. designed the study; J.E.H., A.M., and E.A. supervised data collection; N.M. performed the statistical analysis; J.E.H. wrote the first draft of the manuscript, which was reviewed and edited by all other authors. All authors approved the final version.

\section{Conflicts of interest}

There are no conflicts of interest.

\section{References}

1. World Bank. Information and Communications for Development 2012: Maximizing Mobile. Washington, DC: World Bank. DOI: 10.1596/978-0-8213-8991-1; website: http://www. worldbank.org/ict/IC4D2012. License: Creative Commons Attribution CC BY 3.0 [Accessed 14 January 2016].
2. Lester RT, Ritvo P, Mills EJ, Kariri A, Karanja S, Chung MH, et al. Effects of a mobile phone short message service on antiretroviral treatment adherence in Kenya (WelTel Kenya1): a randomised trial. Lancet 2010; 376:1838-1845.

3. Pop-Eleches C, Thirumurthy $\mathrm{H}$, Habyarimana JP, Zivin JG, Goldstein MP, de Walque D, et al. Mobile phone technologies improve adherence to antiretroviral treatment in a resourcelimited setting: a randomized controlled trial of text message reminders. AIDS 2011; 25:825-834.

4. Maduka $\mathrm{O}$, Tobin-West $\mathrm{Cl}$. Adherence counseling and reminder text messages improve uptake of antiretroviral therapy in a tertiary hospital in Nigeria. Niger J Clin Pract 2013; 16:302308.

5. Mbuagbaw L, van der Kop ML, Lester RT, Thirumurthy H, PopEleches $C$, Ye C, et al. Mobile phone text messages for improving adherence to antiretroviral therapy (ART): an individual patient data meta-analysis of randomised trials. BMJ Open 2013; 3:e003950.

6. Shet A, De Costa A, Kumarasamy N, Rodrigues R, Rewari BB, Ashorn $P$, et al. Effect of mobile telephone reminders on treatment outcome in HIV: evidence from a randomised controlled trial in India. BMJ 2014; 349:g5978.

7. da Costa TM, Barbosa BJ, Gomes e Costa DA, Sigulem D, de Fatima Marin $\mathrm{H}$, Filho AC, et al. Results of a randomized controlled trial to assess the effects of a mobile SMS-based intervention on treatment adherence in HIV/AIDS-infected Brazilian women and impressions and satisfaction with respect to incoming messages. Int J Med Inform 2012; 81:257-269.

8. Sabin LL, Bachman DeSilva M, Gill CJ, Zhong L, Vian T, Xie W, et al. Improving adherence to antiretroviral therapy with triggered real-time text message reminders: The China Adherence Through Technology Study. I Acquir Immune Defic Syndr 2015; 69:551-559.

9. Orrell C, Cohen K, Mauff K, Bangsberg DR, Maartens G, Wood $R$. A randomised controlled trial of real-time electronic adherence monitoring with text message dosing reminders in people starting first-line antiretroviral therapy. I Acquir $1 \mathrm{~m}$ mune Defic Syndr 2015; 70:495-502.

10. Ware NC, Idoko J, Kaaya S, Biraro IA, Wyatt MA, Agbaji O, et al. Explaining adherence success in sub-Saharan Africa: an ethnographic study. PLoS Med 2009; 6:e11.

11. O'Laughlin KN, Wyatt MA, Kaaya S, Bangsberg DR, Ware NC. How treatment partners help: social analysis of an African adherence support intervention. AIDS Behav 2012; 16:13081315.

12. Binagwaho $A$, Ratnayake $N$. The role of social capital in successful adherence to antiretroviral therapy in Africa. PLOS Med 2009; 6:e18.

13. Bolton P, Wilk CM, Ndogoni L. Assessment of depression prevalence in rural Uganda using symptom and function criteria. Soc Psychiatry Psychiatr Epidemiol 2004; 39:442447.

14. Tsai AC, Bangsberg DR, Frongillo EA, Hunt PW, Muzoora C, Martin JN, et al. Food insecurity, depression and the modifying role of social support among people living with HIV/AIDS in rural Uganda. Soc Sci Med 2012; 74:2012-2019.

15. Bush K, Kivlahan DR, McDonell MB, Fihn SD, Bradley KA. The AUDIT alcohol consumption questions (AUDIT-C): an effective brief screening test for problem drinking. Ambulatory Care Quality Improvement Project (ACQUIP). Alcohol Use Disorders Identification Test. Arch Intern Med 1998; 158:17891795.

16. Broadhead WE, Gehlbach SH, de Gruy FV, Kaplan BH, The Duke-UNC Functional Social Support Questionnaire. Measurement of social support in family medicine patients. Med Care 1988; 26:709-723.

17. Kalichman SC, Simbayi LC, Cloete A, Mthembu PP, Mkhonta RN, Ginindza T. Measuring AIDS stigmas in people living with HIV/AIDS: the Internalized AIDS-Related Stigma Scale. AIDS Care 2009; 21:87-93.

18. Ware NC, Pisarski EE, Tam M, Wyatt MA, Atukunda E, Musiimenta $A$, et al. The Meanings in the messages: how SMS reminders and real-time adherence monitoring improve antiretroviral therapy adherence in rural Uganda. AIDS 2016; 30:1287-1293. 